\title{
Non-Sentinel Lymph Node Metastasis is Hard to Predict by Clinicopathological Factors if SLN Metastasis in Two or Fewer Nodes in Breast Cancer
}

\author{
Miki Hasegawa ${ }^{a}$, Yu Koyama ${ }^{\text {a, }}$, Jun Sakata ${ }^{a}$, Kumiko Tatsuda ${ }^{a}$,Eiko Sakata ${ }^{a}$, Chie Toshikawa ${ }^{a}$, \\ Naoko Manba ${ }^{a}$, Mayuko Ikarashi ${ }^{\mathrm{a}}$, Toshifumi Wakai ${ }^{\mathrm{a}}$
}

\begin{abstract}
Background: The aim of this study was to investigate the association between sentinel lymph node (SLN) and/or non-SLN metastasis and clinicopathological factors in breast cancer.

Methods: We identified 176 invasive breast cancer patients by SLN biopsy (SLNB) and evaluated any association between clinicopathological factors and SLN and/or non-SLN metastasis.

Results: SLN metastasis was significantly associated with age $(\mathrm{P}=$ $0.0231)$, tumor size $(\mathrm{P}=0.0039)$ and lymphovascular involvement (LVI) $(\mathrm{P}=0.0002)$. Non-SLN metastasis was observed in $41.4 \%$ of cases. The involvement of more than three nodes was observed in more than $30 \%$ of cases with SLN metastasis in two or fewer nodes. There was no significant association between non-SLN metastasis and clinicopathological factors.
\end{abstract}

Conclusions: Non-SLN metastasis was apparent in more than $30 \%$ of cases even if SLN metastasis was present in two or fewer nodes but non-SLN metastasis was hard to predict by clinicopathological factors.

Keywords: Breast cancer; Sentinel lymph node; Non-sentinel lymph node; Metastasis

\section{Introduction}

In spite of new tumor markers have been widely studied, axillary lymph node metastasis remains a strong prognos-

\footnotetext{
Manuscript accepted for publication December 3, 2013

${ }^{a}$ Division of Digestive and General Surgery, Niigata University Graduate School of Medical and Dental Sciences, Niigata, Japan

${ }^{\mathrm{b}}$ Corresponding author: Yu Koyama, Division of Digestive and General Surgery, Niigata University Graduate School of Medical and Dental Sciences, 1-757 Asahimachi, Niigata 951-8510, Japan.

Email: yukmy@med.niigata-u.ac.jp
}

doi: http://dx.doi.org/10.14740/jcs206w tic indicator for the patients with invasive breast cancer [13]. Axillary lymph node dissection (ALND) is the standard management approach for preoperatively-diagnosed nodepositive breast cancer [4]. Since the 1990s, the introduction of sentinel lymph node (SLN) biopsy (SLNB) has resulted in changes in the management of the axilla [5]. SLNB for clinically N0 breast cancer and ALND for positive SLN have become the standard procedures.

Recent clinical trials have suggested that there is no difference in outcome between patients with positive SLN if they are treated with ALND or given no further axillary surgery $[6,7]$. These studies raise doubts concerning the role of SLNB. A new trial compared SLNB with the assessment of whether an axillary ultra-sound is negative in patients with small breast cancer [8]. SLN metastasis has been observed in about $30 \%$ of SLNBs [9], so it is important to predict the axillary node status before SLNB. Various clinicopathological factors have been identified as independent predictors of axillary lymph node metastasis in early stage breast cancer [10]. These factors include clinical palpability [11-14], tumor size [11-17], lymphatic or vascular involvement [11-15, 17], tumor grade [11, 14], hormone receptor (HR) status [16, $17]$, age $[12,15,16]$, and molecular subtype classification $[3,10,18-26]$.

Predicting the non-SLN status is important because the ACOSOG Z0011 [6] and IBCSG 23-01 [7] studies both indicated that ALND should be avoided if SLN is positive. Analytical tools have been developed for predicting the risk of non-SLN metastasis following positive SLN [27-33] but these yield a false negative rate of 7-41\% (ALND for $<10 \%$ risk of non-SLN metastasis) [34].

The aim of this study was to investigate: 1 ), the association between SLN metastasis and routinely-used clinicopathological factors; 2), the association between non-SLN metastasis and clinicopathological factors in breast cancer.

\section{Materials and Methods}

\section{Patient selection}

Patients with invasive breast cancer who received SNB at 
Table 1. Association Between SLN Metastasis and Clinicopathological Features $(n=176)$

SLN

Total

$P$ value

Negative (\%)

Positive (\%)

Age

$\begin{array}{lll}\leq 50 & 59 & 44(74.6) \\ >50 & 117 & 103(88.0)\end{array}$

0.0231

umor size

$\begin{array}{lll}\text { T1 } & 138 & 122(88.4) \\ \text { T2 } & 32 & 21(65.6) \\ \text { T3 } & 6 & 4(66.7)\end{array}$

Histological grade

$\begin{array}{lll}\text { I } & 122 & 103(84.4) \\ \text { II } & 30 & 25(83.3) \\ \text { III } & 24 & 19(79.2)\end{array}$

VI

Negative

Positive

ER and/or PR

Negative

Positive

HER2

Negative
Positive

$98(80.3)$

$49(90.7)$

Molecular subtypes

$$
\text { Luminal A }
$$

Luminal B

HER2

Triple negative

Ki-67

$$
\begin{aligned}
& \text { Ki-67 }<14 \% \\
& \text { Ki-67 } \geq 14 \%
\end{aligned}
$$

163

$6(46.2)$

$17(89.5)$$$
98 \text { (80.3) }
$$

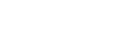$$
74 \text { (87.1) }
$$$$
6 \text { (100) }
$$$$
11 \text { (84.6) }
$$

$$
72
$$$$
85
$$$$
6
$$$$
13
$$

0.0039

0.8171

$141(86.5)$

$130(82.8)$$$
56 \text { (77.8) }
$$

0.0002

22 (13.5)

19 (15.6)

5 (16.7)

5 (20.8)

(11.6)

2 (33.3)

15 (25.4)

14 (12.0)

16 (11.6)

$$
2 \text { (33.3) }
$$

$$
\begin{aligned}
& 22(13.5) \\
& 7(53.8)
\end{aligned}
$$$$
2 \text { (10.5) }
$$$$
27 \text { (17.2) }
$$

0.0859

24 (19.7)

5 (9.3)

0.4591

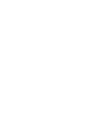

0.2965

$16(22.2)$

11 (12.9)

$0(0)$

2 (15.4)

0.3388

18 (18.9)

11 (13.6)

SLN: sentinel lymph node; LVI: lymphovascular involvement; ER: estrogen receptor; PR: progesterone receptor. 
Table 2. Multivariate Analysis of Clinicopathologic Factors

\begin{tabular}{llll}
\hline & & P value & RR (95\% CI) \\
\hline Age & $>50$ vs. $\leq 50$ & 0.043 & $2.541(1.029-6.274)$ \\
Tumor size & T1 vs T2, T3 & 0.004 & $4.066(1.569-10.533)$ \\
LVI & $(-)$ ve vs. $(+)$ ve & 0.015 & $4.924(1.367-17.744)$ \\
\hline
\end{tabular}

RR: relative risk; Cl: confidence interval; LVI: lymphovascular involvement.

Niigata University Hospital between January 2010 and December 2012 were enrolled into this study. ALND was performed in patients with macro- and micrometastasis in SLN, however, ALND was avoided in patients with isolated tumor cells in SLN. This study included a retrospective chart review. Patients with a complete data of clinicopathological factors including age, clinical and pathological tumor size, HR and HER2 status, and Ki-67 labeling index were enrolled $(n=176)$. These data of patients were analyzed following approval from the Institutional Review Board.

\section{Pathological assessment}

Immunohistochemical (IHC) ER and PR status was assessed and tumors were deemed positive for each receptor if at least $10 \%$ of the invasive tumor cells in a section exhibited nuclear staining. HER2 expression was examined by IHC, and a gene amplification assay using fluorescence in situ hybridization (FISH) was utilized in cases when it was difficult to decide the HER2 status by IHC. Ki-67 was also examined by IHC, and the results are expressed as the percentage of tumor cells stained by the antibody as described previously [35]. Hematoxylin eosin staining was used to assess lymphovascular involvement (LVI) as well as histological grading, which was defined according to Scarff-Bloom-Richardson system [36]. SLN metastasis was judged by intraoperative frozen section and was re-examined using fixed sections and re-judged postoperatively. The staging of breast cancer was defined by the TNM classification as proposed by the American Joint Committee on Cancer (AJCC). All of the IHC judgements were performed by several well-trained pathologists.

Patients were assigned into four subgroups, as proposed in the St Gallen International Expert Consensus [37], according to the results of their ER, PR, HER2 status and Ki-67 leveling index [38]. These groups were: the luminal A group with ER positive or PR positive, Her2 negative and Ki-67 < $14 \%$; the luminal B group with ER positive or PR positive,
Her2 positive or Ki-67 $\geq 14 \%$; the HER 2 group with ER negative, PR negative and Her2 positive; and the triple negative group with ER negative, PR negative and Her2 negative.

\section{Statistical analysis}

We examined the relationship between SLN metastasis and clinicopathological factors including ER and/or PgR status, Her2 status, subtype classification and Ki-67 expression. Univariate analysis was performed using the Chi-square test, and multivariate analysis was performed using the logistic regression model. Statistical significance was defined as $\mathrm{P}$ $<0.05$.

\section{Results}

\section{Patient characteristics and clinicopathological factors}

A total of 176 patients were enrolled during the study period and all of these patients were female and 29 patients had SLN metastasis (16.5\%). The mean age of the patients was 57.3 years old, and SLN metastasis was more frequent in younger patients $(\mathrm{P}=0.0231)$. Tumor size was also associated with SN metastasis, and SLN metastasis was more frequent in larger tumors $(\mathrm{P}=0.0039)$. LVI was also strongly associated with SLN metastasis $(\mathrm{P}=0.0002)$ (Table 1). Multivariate analysis showed that age, tumor size and LVI were significant factors for predicting SLN metastasis (Table 2). The relative risk of younger age, large tumor size and prominent LVI was 2.541, 4.066 and 4.924, respectively. There was no significant correlation between SLN metastasis and ER and/or PgR status/Her2 status.

The percentage distribution of molecular subtypes among the 176 patients was as follows: luminal $\mathrm{A}$ in $40.9 \%$; luminal B in 48.3\%; HER2 in 3.4\%; triple negative in 7.4\%. There was no significant association between SLN metastasis and molecular subtype classification. 
Table 3. Association Between SLN Metastasis and Non-SLN Metastasis $(n=29)$

\begin{tabular}{|c|c|c|c|c|c|c|}
\hline & \multirow{2}{*}{ Total } & \multicolumn{4}{|c|}{ Number of non-SLN metastasis (\%) } & \multirow{2}{*}{ P value } \\
\hline & & $\mathbf{0}$ & 1 & 2 & $\geq \mathbf{3}$ & \\
\hline SLN metastasis & & & & & & 0.1787 \\
\hline 1 node & 20 & $13(65.0)$ & $5(25.0)$ & $0(0)$ & $2(10.0)$ & \\
\hline 2 nodes & 5 & $3(60.0)$ & $1(20.0)$ & $0(0)$ & $1(20.0)$ & \\
\hline$\geq 3$ nodes & 4 & $1(25.0)$ & $2(50.0)$ & $1(25.0)$ & $0(0)$ & \\
\hline
\end{tabular}

We divided patients into two groups using a cut-off of Ki-67 of 14\% according to the St Gallen consensus [37]. Patients with $\mathrm{Ki}-67 \geq 14 \%$ were categorized as the high Ki-67 group, and those with $\mathrm{Ki}-67<14 \%$ as the low $\mathrm{Ki}-67$ group. There was no significant association between Ki-67 expression and SLN metastasis.

\section{Non-SLN metastasis and clinicopathological factors}

Non-SLN metastasis was in detected in 12 out of the 29 positive SLN patients (41.4\%). Among non-SLN metastases, only one positive node was observed in eight patients $(66.7 \%)$, two positive nodes were observed in one patient $(8.3 \%)$, and more than three positive nodes were observed in three patients (25\%). A total of 16 patients (64.0\%) with SLN metastasis showed two or less positive nodes with no further axillary node metastasis but nine patients $(36.0 \%)$ had nonSLN metastasis. More than three non-SLN metastases were observed in three patients (12\%) with SLN metastasis with two or less positive nodes (Table 3 ).

Clinicopathological factors were examined in the patients with non-SLN metastasis, but there significant association was observed between non-SLN metastasis and clinicopathological factors (Table 4).

\section{Discussion}

SLNB for clinically node-negative breast cancer has become a standard procedure worldwide and it is important to determine pathologically whether the node is negative before surgery. In this study, we observed that age, tumor size and LVI are significantly associated with SLN metastasis. Parameters such as a patient age of less than 50 years, large tumor size and prominent LVI were shown to indicate a higher likelihood of the patient being SLN positive. These findings are in accordance with previous reports [11-17], which have also indicated HR and histological grade are good predictors for positive SLN $[11,14,16,17]$. We could not find any association between HR status/histological grade and SLN metastasis. The discrepancy between previous reports and our results may result from the different relative numbers of patients in each category with $89.2 \% \mathrm{HR}$ positive and $78.4 \%$ grade I in this study.

In contrast to previous reports, this study did not find any association between the molecular subtype and SLN metastasis $[3,10,18-26]$. One possible explanation for the discrepancy between previous reports and our results is the distribution among subtypes, which could affect the results. The HER 2 type was very infrequent (3.4\%), which may contribute to the absence of SLN metastasis in the HER2 subtype in this study.

The ACOSOG Z0011 study [6] showed that SLNB alone without ALND results in extremely low locoregional recurrence and excellent overall survival comparable to completed ALND in patients with SLN metastasis at two or fewer nodes. We showed that there is greater than $30 \%$ risk of non-SLN metastasis, and more than $10 \%$ of patients risk having three or more metastases nodes, even if there is SLN metastasis in two or fewer nodes. Our results are comparable to the ALND group in the ACOSOG Z0011 study with similar overall survival and disease-free survival in both groups. Systemic therapy and radiation therapy may have contributed to these results with more than $95 \%$ of patients in each group received ajduvant systemic therapy, and more than $88 \%$ of patients in each group receiving whole-breast radiation therapy. The possibility exists that more advanced disease in the ALND group was cured by the aggressive ALND procedure. The baseline characteristics of the ACOSOG Z0011 study showed that the number of patients with LN metastasis at one or fewer nodes in the SLND alone group was higher than the ALND group. Systemic therapies includ- 
Table 4. Association Between Non-SLN Metastasis and Clinicopathological Features $(n=29)$

\begin{tabular}{|c|c|c|c|c|}
\hline & \multirow{2}{*}{ Total } & \multicolumn{2}{|c|}{ SLN } & \multirow{2}{*}{ P value } \\
\hline & & Negative (\%) & Positive (\%) & \\
\hline Age & & & & 0.3625 \\
\hline$\leq 50$ & 15 & $10(66.7)$ & $5(33.3)$ & \\
\hline$>50$ & 14 & $7(50.0)$ & $7(50.0)$ & \\
\hline Tumor size & & & & 0.8888 \\
\hline $\mathrm{T} 1$ & 16 & $10(62.5)$ & $6(37.5)$ & \\
\hline $\mathrm{T} 2$ & 11 & $6(54.5)$ & $5(45.5)$ & \\
\hline $\mathrm{T} 3$ & 2 & $1(50.0)$ & $1(50.0)$ & \\
\hline Histological grade & & & & 0.0618 \\
\hline I & 19 & $14(73.7)$ & $5(26.3)$ & \\
\hline II & 5 & $1(20.0)$ & $4(80.0)$ & \\
\hline III & 5 & $2(40.0)$ & $3(60.0)$ & \\
\hline LVI & & & & 0.0638 \\
\hline Negative & 22 & $15(68.2)$ & $7(31.8)$ & \\
\hline Positive & 7 & $2(28.6)$ & $5(71.4)$ & \\
\hline ER and/or PR & & & & 0.7975 \\
\hline Negative & 2 & $1(50.0)$ & $1(50.0)$ & \\
\hline Positive & 27 & $16(59.3)$ & $11(40.7)$ & \\
\hline HER2 & & & & 0.3527 \\
\hline Negative & 24 & $15(62.5)$ & $9(37.5)$ & \\
\hline Positive & 5 & $2(40.0)$ & $3(60.0)$ & \\
\hline Molecular subtypes & & & & 0.8888 \\
\hline Luminal A & 16 & $10(62.5)$ & $6(37.5)$ & \\
\hline Luminal B & 11 & $6(54.5)$ & $5(45.5)$ & \\
\hline HER2 & 2 & $1(50.0)$ & $1(50.0)$ & \\
\hline Triple negative & & & & 0.7276 \\
\hline \multicolumn{5}{|l|}{ Ki-67 } \\
\hline $\mathrm{Ki}-67<14 \%$ & 18 & $11(61.1)$ & $7(38.9)$ & \\
\hline $\mathrm{Ki}-67 \geq 14 \%$ & 11 & $6(54.5)$ & $5(45.5)$ & \\
\hline
\end{tabular}

SLN: sentinel lymph node; LVI: lymphovascular involvement; ER: estrogen receptor; PR: progesterone receptor. 
ing hormone therapy, cytotoxic chemotherapy and/or molecular targeting drugs remain highly important in breast cancer treatment. In addition, surgeons who have a critical role in breast cancer treatment should be trained to master the less invasive skill of ALND.

\section{Conclusion}

SLN metastasis was associated with younger age, large tumor size and prominent LVI. Non-SLN metastasis was apparent in more than $30 \%$ of cases even if SLN metastasis occurred in two or less nodes. Non-SLN metastasis was hard to predict by clinicopathologic factors.

\section{Financial Disclosure}

We declare that we have no conflict of interest.

\section{References}

1. Rosen PP, Groshen S, Kinne DW, Norton L. Factors influencing prognosis in node-negative breast carcinoma: analysis of $767 \mathrm{~T} 1 \mathrm{~N} 0 \mathrm{M} 0 / \mathrm{T} 2 \mathrm{~N} 0 \mathrm{M} 0$ patients with longterm follow-up. J Clin Oncol. 1993;11(11):2090-2100.

2. Consensus statement: treatment of early-stage breast cancer. National Institutes of Health Consensus Development Panel. J Natl Cancer Inst Monogr. 1992;(11):15.

3. Lee JH, Kim SH, Suh YJ, Shim BY, Kim HK. Predictors of axillary lymph node metastases (ALNM) in a Korean population with T1-2 breast carcinoma: triple negative breast cancer has a high incidence of ALNM irrespective of the tumor size. Cancer Res Treat. 2010;42(1):30-36.

4. Cserni G, Bianchi S, Vezzosi V, Arisio R, Bori R, Peterse JL, Sapino A, et al. Sentinel lymph node biopsy and non-sentinel node involvement in special type breast carcinomas with a good prognosis. Eur J Cancer. 2007;43(9):1407-1414.

5. Giuliano AE, Kirgan DM, Guenther JM, Morton DL. Lymphatic mapping and sentinel lymphadenectomy for breast cancer. Ann Surg. 1994;220(3):391-398; discussion 398-401.

6. Giuliano AE, Hunt KK, Ballman KV, Beitsch PD, Whitworth PW, Blumencranz PW, Leitch AM, et al. Axillary dissection vs no axillary dissection in women with invasive breast cancer and sentinel node metastasis: a randomized clinical trial. JAMA. 2011;305(6):569-575.

7. Galimberti V, Cole BF, Zurrida S, Viale G, Luini A, Veronesi $\mathrm{P}$, Baratella $\mathrm{P}$, et al. Axillary dissection versus no axillary dissection in patients with sentinel-node micrometastases (IBCSG 23-01): a phase 3 randomised controlled trial. Lancet Oncol. 2013;14(4):297-305.
8. Gentilini O, Veronesi U. Abandoning sentinel lymph node biopsy in early breast cancer? A new trial in progress at the European Institute of Oncology of Milan (SOUND: Sentinel node vs Observation after axillary UltraSouND). Breast. 2012;21(5):678-681.

9. Canavese G, Gipponi M, Catturich A, Vecchio C, Tomei D, Nicolo G, Carli F, et al. Technical issues and pathologic implications of sentinel lymph node biopsy in early-stage breast cancer patients. J Surg Oncol. 2001;77(2):81-87; discussion 88 .

10. Crabb SJ, Cheang MC, Leung S, Immonen T, Nielsen TO, Huntsman DD, Bajdik CD, et al. Basal breast cancer molecular subtype predicts for lower incidence of axillary lymph node metastases in primary breast cancer. Clin Breast Cancer. 2008;8(3):249-256.

11. Barth A, Craig PH, Silverstein MJ. Predictors of axillary lymph node metastases in patients with T1 breast carcinoma. Cancer. 1997;79(10):1918-1922.

12. Olivotto IA, Jackson JS, Mates D, Andersen S, Davidson W, Bryce CJ, Ragaz J. Prediction of axillary lymph node involvement of women with invasive breast carcinoma: a multivariate analysis. Cancer. 1998;83(5):948955.

13. Silverstein MJ, Gierson ED, Waisman JR, Colburn WJ, Gamagami P. Predicting axillary node positivity in patients with invasive carcinoma of the breast by using a combination of $\mathrm{T}$ category and palpability. J Am Coll Surg. 1995;180(6):700-704.

14. Silverstein MJ, Skinner KA, Lomis TJ. Predicting axillary nodal positivity in 2282 patients with breast carcinoma. World J Surg. 2001;25(6):767-772.

15. Gajdos C, Tartter PI, Bleiweiss IJ. Lymphatic invasion, tumor size, and age are independent predictors of axillary lymph node metastases in women with $\mathrm{T} 1$ breast cancers. Ann Surg. 1999;230(5):692-696.

16. Gann PH, Colilla SA, Gapstur SM, Winchester DJ, Winchester DP. Factors associated with axillary lymph node metastasis from breast carcinoma: descriptive and predictive analyses. Cancer. 1999;86(8):1511-1519.

17. Viale G, Zurrida S, Maiorano E, Mazzarol G, Pruneri G, Paganelli G, Maisonneuve P, et al. Predicting the status of axillary sentinel lymph nodes in 4351 patients with invasive breast carcinoma treated in a single institution. Cancer. 2005; 103(3):492-500.

18. Lu X, Wang ZC, Iglehart JD, Zhang X, Richardson AL. Predicting features of breast cancer with gene expression patterns. Breast Cancer Res Treat. 2008;108(2):191-201.

19. Liu H, Fan Q, Zhang Z, Li X, Yu H, Meng F. BasalHER2 phenotype shows poorer survival than basal-like phenotype in hormone receptor-negative invasive breast cancers. Hum Pathol. 2008;39(2):167-174.

20. Van Calster B, Vanden Bempt I, Drijkoningen M, Pochet N, Cheng J, Van Huffel S, Hendrickx W, et al. Axillary lymph node status of operable breast cancers by com- 
bined steroid receptor and HER-2 status: triple positive tumours are more likely lymph node positive. Breast Cancer Res Treat. 2009;113(1):181-187.

21. Kim MJ, Ro JY, Ahn SH, Kim HH, Kim SB, Gong G. Clinicopathologic significance of the basal-like subtype of breast cancer: a comparison with hormone receptor and Her2/neu-overexpressing phenotypes. Hum Pathol. 2006;37(9):1217-1226.

22. Nguyen PL, Taghian AG, Katz MS, Niemierko A, Abi Raad RF, Boon WL, Bellon JR, et al. Breast cancer subtype approximated by estrogen receptor, progesterone receptor, and HER-2 is associated with local and distant recurrence after breast-conserving therapy. J Clin Oncol. 2008;26(14):2373-2378.

23. Voduc KD, Cheang MC, Tyldesley S, Gelmon K, Nielsen TO, Kennecke H. Breast cancer subtypes and the risk of local and regional relapse. J Clin Oncol. 2010;28(10):1684-1691.

24. Reyal F, Rouzier R, Depont-Hazelzet B, Bollet MA, Pierga JY, Alran S, Salmon RJ, et al. The molecular subtype classification is a determinant of sentinel node positivity in early breast carcinoma. PLoS One. 2011;6(5):e20297.

25. Buglioni S, Di Filippo F, Terrenato I, Casini B, Gallo E, Marandino F, Maini CL, et al. Quantitative molecular analysis of sentinel lymph node may be predictive of axillary node status in breast cancer classified by molecular subtypes. PLoS One. 2013;8(3):e58823.

26. Mazouni C, Rimareix F, Mathieu MC, Uzan C, Bourgier C, Andre F, Delaloge S, et al. Outcome in breast molecular subtypes according to nodal status and surgical procedures. Am J Surg. 2013;205(6):662-667.

27. Krag DN, Anderson SJ, Julian TB, Brown AM, Harlow SP, Costantino JP, Ashikaga T, et al. Sentinel-lymphnode resection compared with conventional axillarylymph-node dissection in clinically node-negative patients with breast cancer: overall survival findings from the NSABP B-32 randomised phase 3 trial. Lancet Oncol. 2010;11(10):927-933.

28. Van Zee KJ, Manasseh DM, Bevilacqua JL, Boolbol SK, Fey JV, Tan LK, Borgen PI, et al. A nomogram for predicting the likelihood of additional nodal metastases in breast cancer patients with a positive sentinel node biopsy. Ann Surg Oncol. 2003;10(10):1140-1151.

29. Kohrt HE, Olshen RA, Bermas HR, Goodson WH, Wood DJ, Henry S, Rouse RV, et al. New models and online calculator for predicting non-sentinel lymph node status in sentinel lymph node positive breast cancer pa- tients. BMC Cancer. 2008;8:66.

30. Barranger E, Coutant C, Flahault A, Delpech Y, Darai E, Uzan S. An axilla scoring system to predict non-sentinel lymph node status in breast cancer patients with sentinel lymph node involvement. Breast Cancer Res Treat. 2005;91(2):113-119.

31. Pal A, Provenzano E, Duffy SW, Pinder SE, Purushotham AD. A model for predicting non-sentinel lymph node metastatic disease when the sentinel lymph node is positive. Br J Surg. 2008;95(3):302-309.

32. Degnim AC, Reynolds C, Pantvaidya G, Zakaria S, Hoskin T, Barnes S, Roberts MV, et al. Nonsentinel node metastasis in breast cancer patients: assessment of an existing and a new predictive nomogram. Am J Surg. 2005;190(4):543-550.

33. Katz A, Smith BL, Golshan M, Niemierko A, Kobayashi W, Raad RA, Kelada A, et al. Nomogram for the prediction of having four or more involved nodes for sentinel lymph node-positive breast cancer. J Clin Oncol. 2008;26(13):2093-2098.

34. Berrang TS, Lesperance M, Truong PT, Walter C, Hayashi AH, Olivotto IA. Which prediction models best identify additional axillary disease after a positive sentinel node biopsy for breast cancer? Breast Cancer Res Treat. 2012;133(2):695-702.

35. Jones RL, Salter J, A'Hern R, Nerurkar A, Parton M, Reis-Filho JS, Smith IE, et al. Relationship between oestrogen receptor status and proliferation in predicting response and long-term outcome to neoadjuvant chemotherapy for breast cancer. Breast Cancer Res Treat. 2010;119(2):315-323.

36. Contesso G, Mouriesse H, Friedman S, Genin J, Sarrazin $\mathrm{D}$, Rouesse J. The importance of histologic grade in long-term prognosis of breast cancer: a study of 1,010 patients, uniformly treated at the Institut Gustave-Roussy. J Clin Oncol. 1987;5(9):1378-1386.

37. Goldhirsch A, Wood WC, Coates AS, Gelber RD, Thurlimann B, Senn HJ. Strategies for subtypes--dealing with the diversity of breast cancer: highlights of the St. Gallen International Expert Consensus on the Primary Therapy of Early Breast Cancer 2011. Ann Oncol. 2011;22(8):1736-1747.

38. Guiu S, Michiels S, Andre F, Cortes J, Denkert C, Di Leo A, Hennessy BT, et al. Molecular subclasses of breast cancer: how do we define them? The IMPAKT 2012 Working Group Statement. Ann Oncol. 2012;23(12):2997-3006. 